NASA/TM-2009-215604
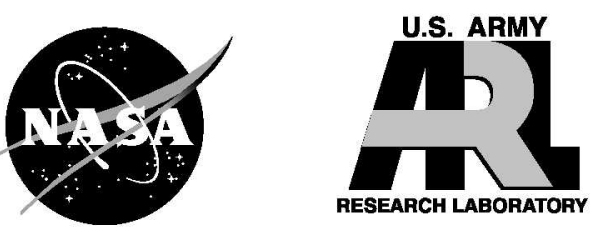

\title{
Unsteady Full Annulus Simulations of a Transonic Axial Compressor Stage
}

Gregory P. Herrick

Glenn Research Center, Cleveland, Ohio

Michael D. Hathaway

U.S. Army Research Laboratory, Glenn Research Center, Cleveland, Ohio

Jen-Ping Chen

The Ohio State University, Columbus, Ohio 


\section{NASA STI Program . . . in Profile}

Since its founding, NASA has been dedicated to the advancement of aeronautics and space science. The NASA Scientific and Technical Information (STI) program plays a key part in helping NASA maintain this important role.

The NASA STI Program operates under the auspices of the Agency Chief Information Officer. It collects, organizes, provides for archiving, and disseminates NASA's STI. The NASA STI program provides access to the NASA Aeronautics and Space Database and its public interface, the NASA Technical Reports Server, thus providing one of the largest collections of aeronautical and space science STI in the world. Results are published in both non-NASA channels and by NASA in the NASA STI Report Series, which includes the following report types:

- TECHNICAL PUBLICATION. Reports of completed research or a major significant phase of research that present the results of NASA programs and include extensive data or theoretical analysis. Includes compilations of significant scientific and technical data and information deemed to be of continuing reference value. NASA counterpart of peer-reviewed formal professional papers but has less stringent limitations on manuscript length and extent of graphic presentations.

- TECHNICAL MEMORANDUM. Scientific and technical findings that are preliminary or of specialized interest, e.g., quick release reports, working papers, and bibliographies that contain minimal annotation. Does not contain extensive analysis.

- CONTRACTOR REPORT. Scientific and technical findings by NASA-sponsored contractors and grantees.
- CONFERENCE PUBLICATION. Collected papers from scientific and technical conferences, symposia, seminars, or other meetings sponsored or cosponsored by NASA.

- SPECIAL PUBLICATION. Scientific, technical, or historical information from NASA programs, projects, and missions, often concerned with subjects having substantial public interest.

- TECHNICAL TRANSLATION. Englishlanguage translations of foreign scientific and technical material pertinent to NASA's mission.

Specialized services also include creating custom thesauri, building customized databases, organizing and publishing research results.

For more information about the NASA STI program, see the following:

- Access the NASA STI program home page at http://www.sti.nasa.gov

- E-mail your question via the Internet to help@ sti.nasa.gov

- Fax your question to the NASA STI Help Desk at 301-621-0134

- Telephone the NASA STI Help Desk at $301-621-0390$

- Write to: NASA Center for AeroSpace Information (CASI) 7115 Standard Drive Hanover, MD 21076-1320 

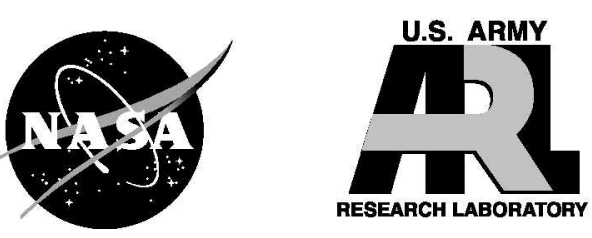

\section{Unsteady Full Annulus Simulations of a Transonic Axial Compressor Stage}

\section{Gregory P. Herrick}

Glenn Research Center, Cleveland, Ohio

Michael D. Hathaway

U.S. Army Research Laboratory, Glenn Research Center, Cleveland, Ohio

Jen-Ping Chen

The Ohio State University, Columbus, Ohio

Prepared for the

47th Aerospace Sciences Meeting

sponsored by the American Institute of Aeronautics and Astronautics

Orlando, Florida, January 5-8, 2009

National Aeronautics and

Space Administration

Glenn Research Center Cleveland, Ohio 44135 
This work was sponsored by the Fundamental Aeronautics Program at the NASA Glenn Research Center.

Level of Review: This material has been technically reviewed by technical management.

Available from

NASA Center for Aerospace Information

7115 Standard Drive

Hanover, MD 21076-1320
National Technical Information Service 5285 Port Royal Road Springfield, VA 22161

Available electronically at http://gltrs.grc.nasa.gov 


\title{
Unsteady Full Annulus Simulations of \\ a Transonic Axial Compressor Stage
}

\author{
Gregory P. Herrick \\ National Aeronautics and Space Administration \\ Glenn Research Center \\ Cleveland, Ohio 44135 \\ Michael D. Hathaway \\ U.S. Army Research Laboratory \\ Glenn Research Center \\ Cleveland, Ohio 44135 \\ Jen-Ping Chen \\ The Ohio State University \\ Columbus, Ohio 43210
}

\begin{abstract}
Two recent research endeavors in turbomachinery at NASA Glenn Research Center have focused on compression system stall inception and compression system aerothermodynamic performance. Physical experiment and computational research are ongoing in support of these research objectives. TURBO, an unsteady, three-dimensional, Navier-Stokes computational fluid dynamics code commissioned and developed by NASA, has been utilized, enhanced, and validated in support of these endeavors. In the research which follows, TURBO is shown to accurately capture compression system flow range-from choke to stall inception - and also to accurately calculate fundamental aerothermodynamic performance parameters. Rigorous full-annulus calculations are performed to validate TURBO's ability to simulate the unstable, unsteady, chaotic stall inception process; as part of these efforts, full-annulus calculations are also performed at a condition approaching choke to further document TURBO's capabilities to compute aerothermodynamic performance data and support a NASA code assessment effort.
\end{abstract}

\section{Introduction}

Turbomachinery generates power and propulsion for a wide variety of applications. Regardless of application, it is imperative that the turbomachinery perform reliably and efficiently. A major focus of research within NASA's Fundamental Aeronautics Program concerns efficient, highly-loaded turbomachinery. An essential part of the research is the development and validation of high-fidelity computational design and analysis tools. Many computational tools have been commissioned, developed, and validated by NASA, and an effort has been undertaken to assess these various tools.

Concurrent with NASA's Fundamental Aeronautics goal for efficient, highly-loaded turbomachinery, the Army Research Laboratory (ARL) has a vested interest in reliable, efficient turbomachinery for the power plants used within the Army's helicopters, tanks, and uninhabited aerial vehicles, inter alia. Reliable, efficient performance of the gas turbine power plant depends on reliable, efficient performance of the turbomachinery compression system. In pursuit of this goal, ARL has conducted extensive research in compression system stall inception and stall control, both experimentally and computationally.

In support of NASA and ARL objectives, an extensive research effort has been performed on the NASA Stage 35 single-stage transonic axial compressor. Physical experiments have been performed on Stage 35 at Glenn Research Center, and computational research has advanced using several computational fluid dynamics codes developed by NASA. In the research which follows, the TURBO code is applied to simulate three-dimensional, full-annulus, unsteady, time-accurate simulations of Stage 35, with the 
inclusion of a temporally accurate, spatially precise sliding interface as well as gridded rotor tip clearances. Such simulations - expending tremendous quantities of computational resources for long periods of time - are necessary when attempting to capture the three-dimensional, unsteady, aperiodic flow preceding and undergoing rotating stall. In other research efforts supporting these NASA and ARL objectives, these large-scale TURBO simulations have provided valuable insight into the stall inception process, though never intended to explicitly replicate the stalling process of Stage 35 per second. This research documents TURBO's performance in capturing mass-flow and pressure-ratio performance of the Stage 35 transonic axial compressor for flow conditions from choke to stall, with additional investigation of aerothermodynamic performance approaching choke.

\section{Flow Solver}

TURBO is a physics-based simulation tool for multistage turbomachinery. The solver computes the fluid conservation laws without ad hoc modeling of any flow phenomena other than models required for turbulence. This code solves the unsteady Reynolds-averaged Navier-Stokes equations and a decoupled k- $\varepsilon$ turbulence model developed by Zhu and Shih (Ref. 1). To facilitate the rotor-stator interaction studied in this effort, TURBO employs a sliding interface technique implemented by Chen and Barter (Ref. 2) in which conservative variables are interpolated across blade row interfaces. The code is implemented in a portable, scalable form for distributed-memory parallel computers using MPI message passing. The parallel implementation employs domain decomposition and supports general multiblock grids with arbitrary grid-block connectivity. The solution algorithm is a Newton iterative implicit time-accurate scheme with characteristics-based finite-volume spatial discretization. The Newton subiterations are solved using a concurrent block-Jacobi symmetric Gauss-Seidel (BJ-SGS) relaxation scheme. Because all of the fundamental fluid mechanics are computed, the code is capable of capturing the nonlinear characteristics of the flow fields of interest. With the actual modeling of the grid movement of the blade rows in relative motion, this code is capable of computing the unsteady interactions between blade rows. Details of the flow solver are given by Chen and Whitfield (Ref. 3). The approach to parallelization for large-scale, complex problems is discussed by Chen and Briley (Ref. 4).

\section{Stage 35 Transonic Axial Compressor Stage}

The NASA single-stage research compressor Stage 35, which is representative of an advanced transonic compressor core, is studied in this research. A schematic of the Stage 35 test rig is pictured in Figure 1 and the compressor geometry is depicted in Figure 2. The design parameters for Stage 35 are listed in Table 1. Stage 35 produces a total-to-total pressure ratio of 1.8 at a mass flow rate of $20.2 \mathrm{~kg} / \mathrm{s}$ at the design speed of $17189 \mathrm{rpm}$. Details of the design, geometry, operating conditions, and early experimental results are available from Reid and Moore (Ref. 5).

\section{Computational Grid}

This effort follows previous TURBO research studies on Stage 35 by Hathaway et al. (Ref. 6) and Chen et al. (Refs. 7 and 8). For this effort, following the previous TURBO stall inception research on Stage 35, three blade rows are gridded. In addition to the rotor and the stator of the turbomachinery compression system, an inlet row precedes the rotor here. This inlet row allows for the activation of injectors to introduce additional (air) flow for purposes of stall control. In this study, the "injectors" are inactive, and the inlet blade row merely provides valuable additional ducting volume to better, but not completely, replicate the geometry of the physical Stage 35 test rig. 


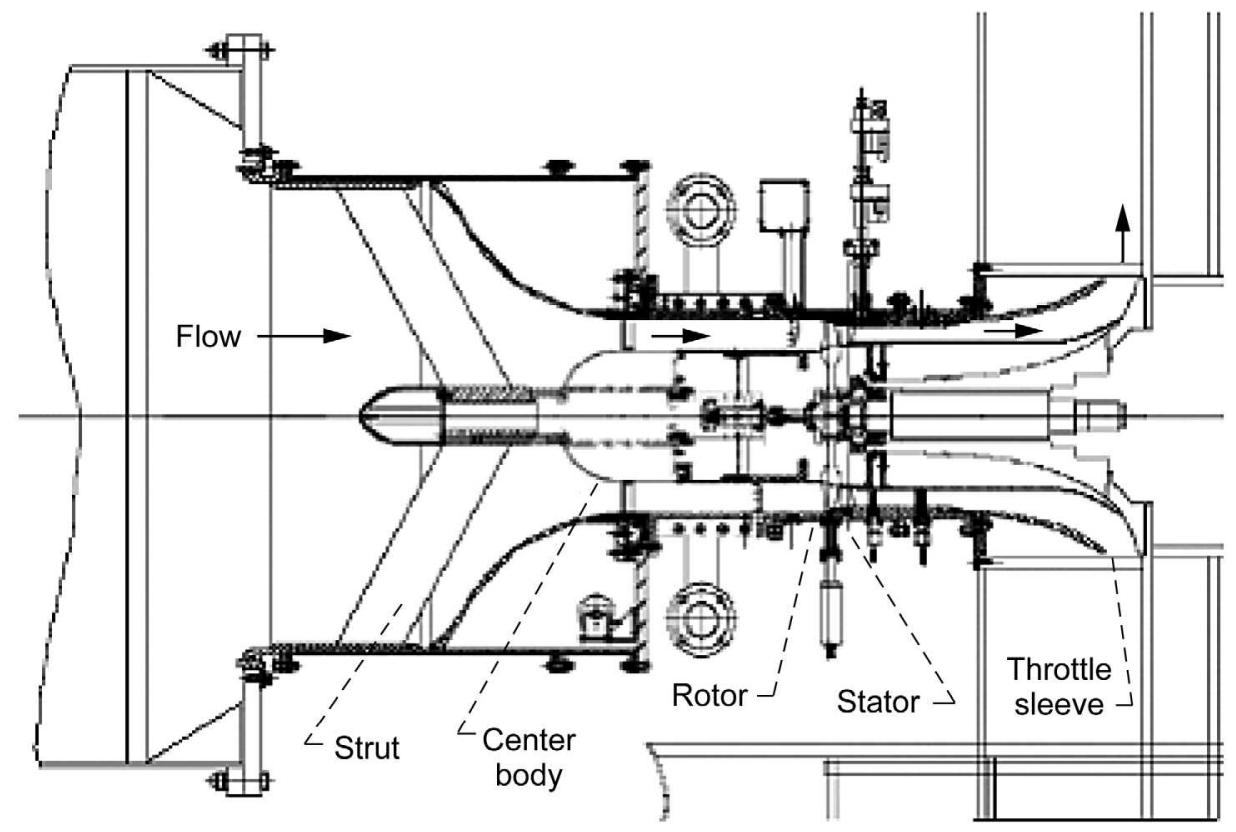

Figure 1.-Stage 35 physical test rig.

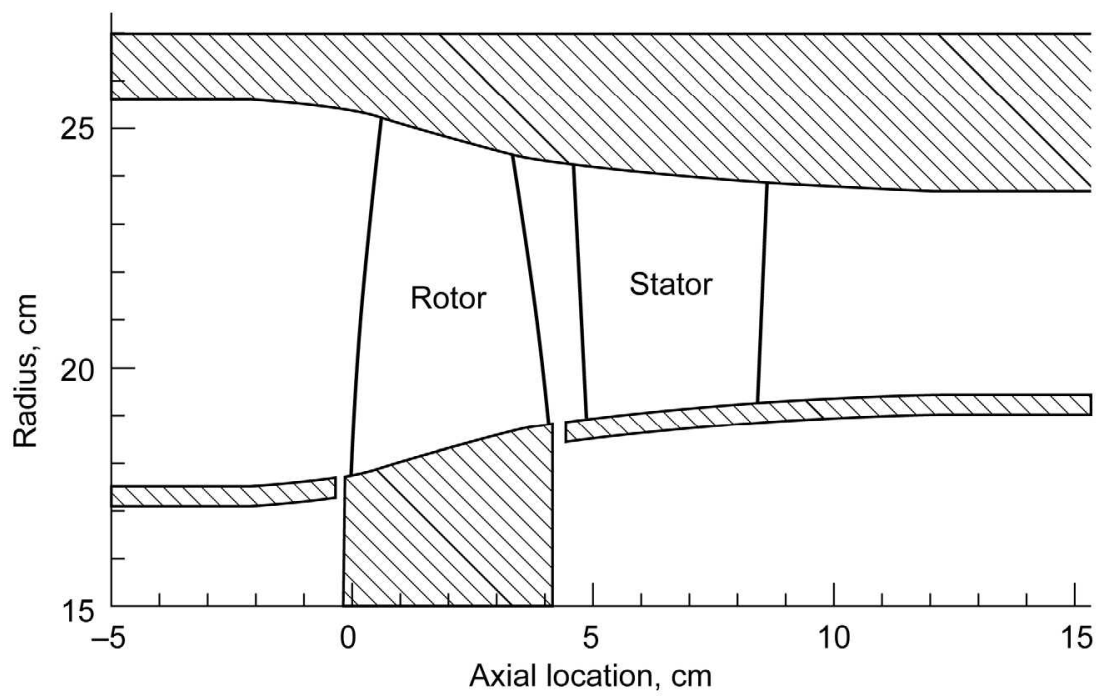

Figure 2.-Stage 35 compressor geometry.

TABLE 1.-STAGE 35 DESIGN PARAMETERS

\begin{tabular}{|l|l|}
\hline Rotor speed at 100 percent speed & $17188.7 \mathrm{rpm}$ \\
\hline Tip speed at 100 percent speed & $454.456 \mathrm{~m} / \mathrm{s}$ \\
\hline Hub/tip radius ratio & 0.7 \\
\hline Rotor aspect ratio & 1.19 \\
\hline Stator aspect ratio & 1.26 \\
\hline Rotor blade count & 36 \\
\hline Stator vane count & 46 \\
\hline
\end{tabular}




\section{Full Annulus Grids}

From experimental research on the Stage 35 test rig, Bright et al. (Ref. 9) concluded that, "... our high-speed stage under normal stalling condition is considered a "modal" machine, since modal instabilities dominate the pre-stall behavior with some added "pip" instabilities present just before stall." Near the stall boundary, the flow field becomes inherently three-dimensional, unsteady, and aperiodic. The physical machine stalls in response to both long-wavelength circumferential modes and higherfrequency perturbations. Consequently, Stage 35 is resolved herein using full annulus grids. These full annulus grids are depicted in Figure 3; a clearer picture of the grids for single inlet/injector, rotor, and stator passages follows in Figure 4.

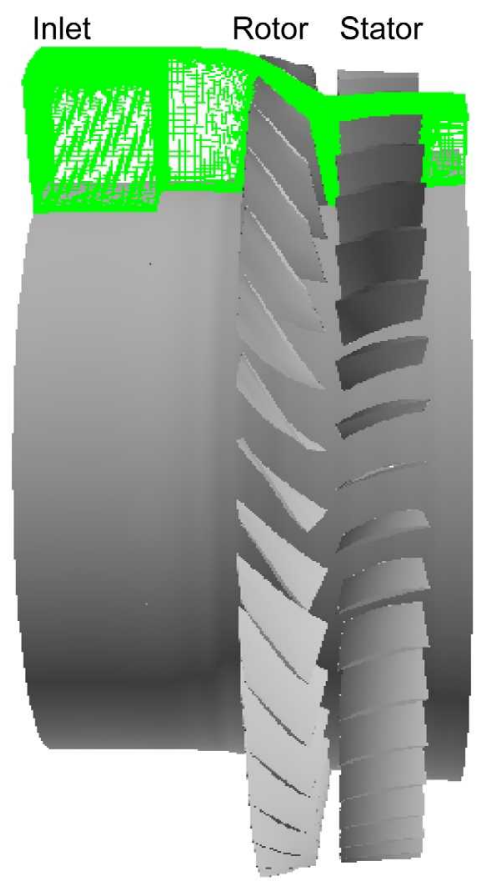

Figure 3.-Stage 35 full annulus CFD grid.

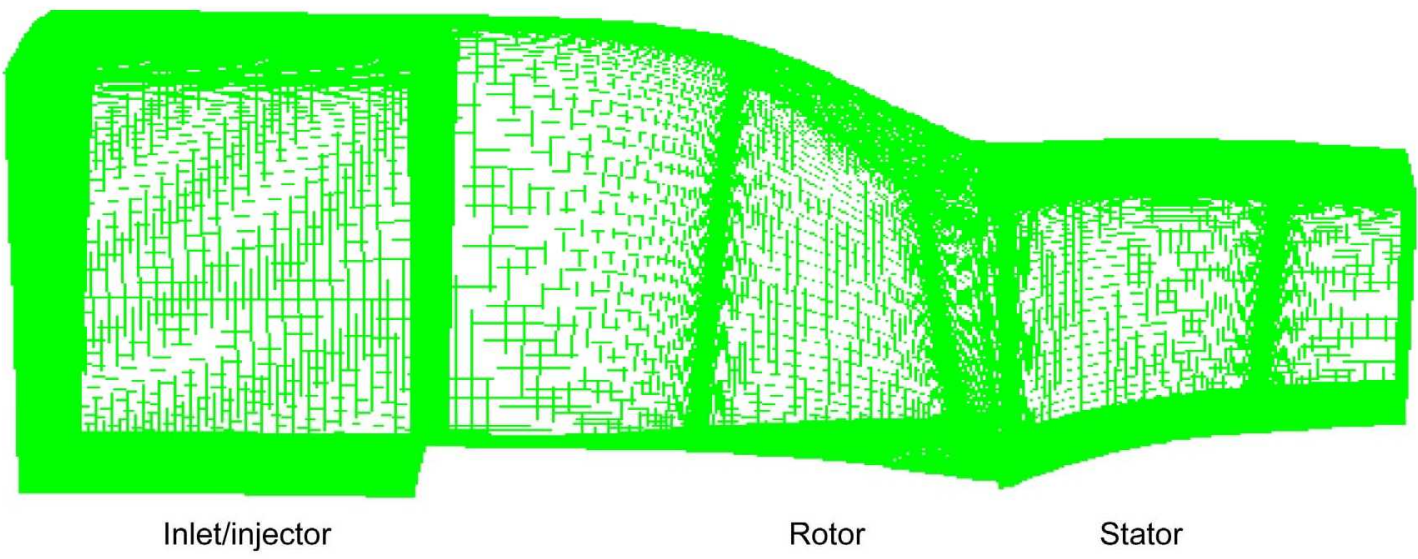

Figure 4.-Stage 35 single passage CFD grid. 


\section{Tip Clearance Grids}

Differentiating this work from prior research by Chen et al. (Refs. 7 and 8 ) and Hathaway et al. (Ref. 6) is the inclusion of gridded rotor tip clearance regions here. Previous stall inception research on Stage 35 using TURBO has employed modeled, periodic rotor tip clearance models like those described by Kirtley et al. (Ref. 10) Much previous research has shown tip clearance flow phenomena to be highly relevant to the stall inception process for many compression systems, and this has motivated gridding these regions to better resolve their flow characteristics. However, limited computational resources and previous software infrastructure issues have effectively prohibited gridding these regions in previous research efforts. The rotor tip clearance grids used in this study are pictured in Figure 5 (plan view of leading edge), Figure 6 (plan view of trailing edge), and Figure 7 (plan view of mid-chord). A summary of Stage 35 grid parameters is provided in Table 2.

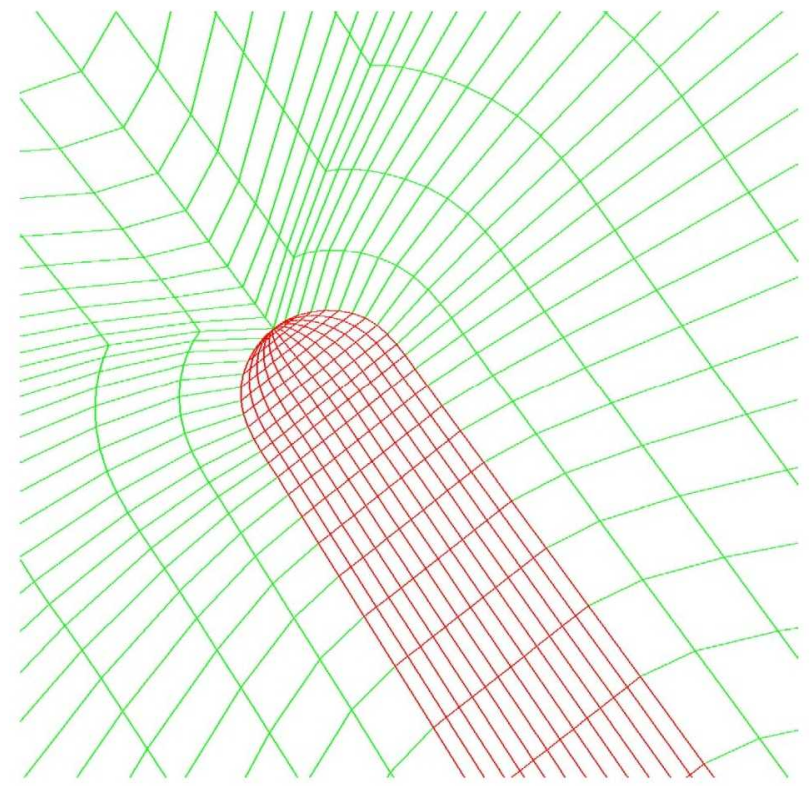

Figure 5.-Tip clearance grid at leading edge.

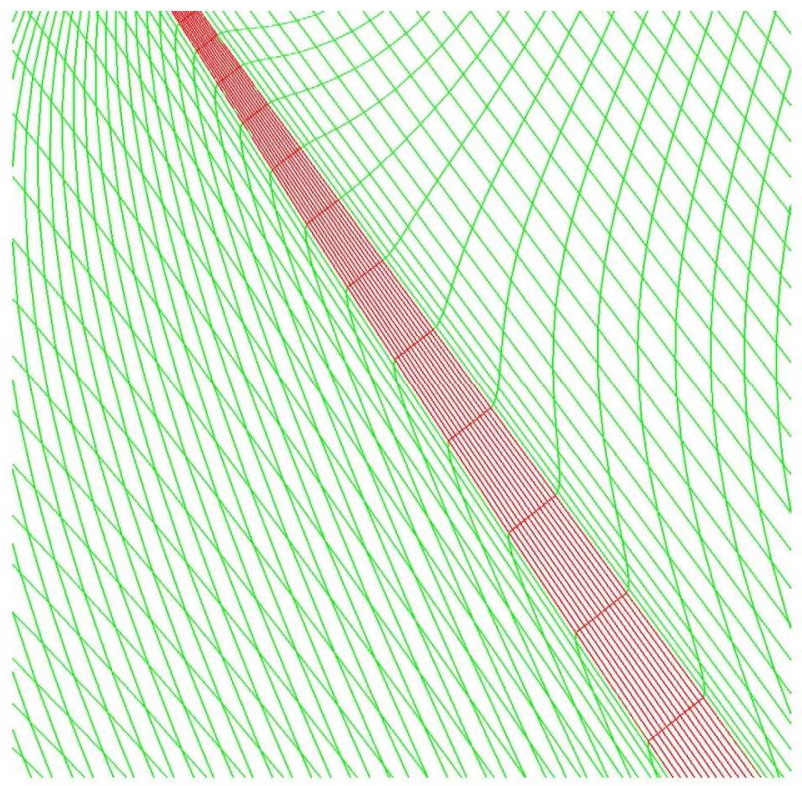

Figure 7.-Tip clearance grid at mid-chord.

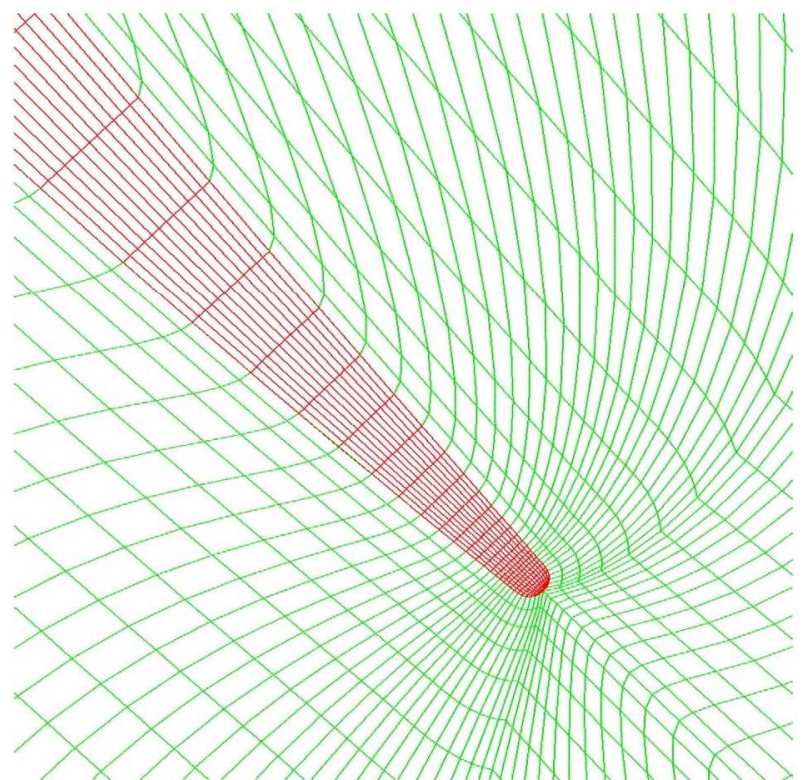

Figure 6.-Tip clearance grid at trailing edge.

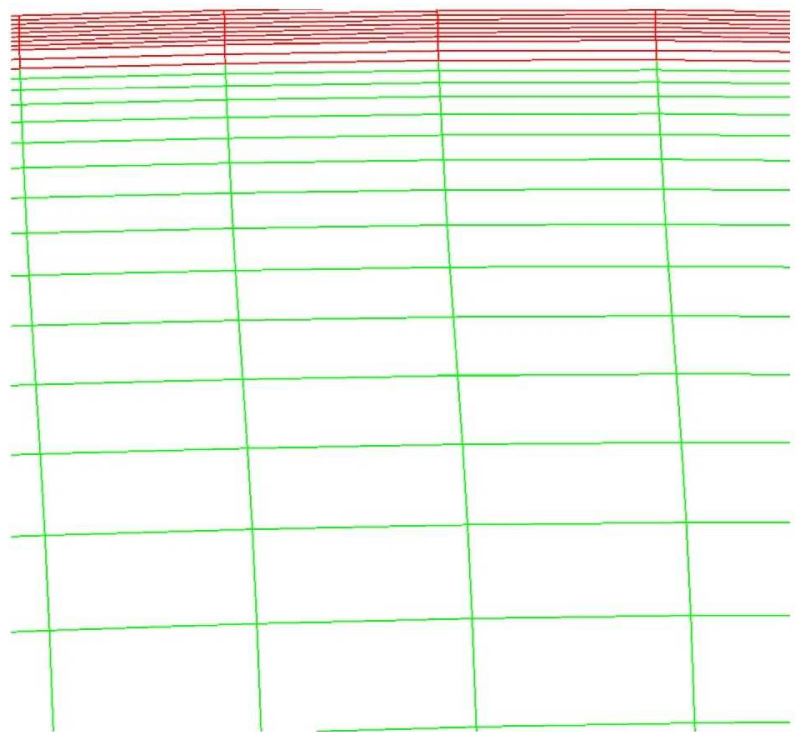

Figure 8.-Tip clearance grid at spanwise distribution. 
TABLE 2.-STAGE 35 CFD GRID PARAMETERS

\begin{tabular}{|l|c|c|c|c|c|}
\hline \multicolumn{1}{|c|}{ Entity } & NI & NJ & NK & Axial partitions & Quantity \\
\hline Inlet/injector & 51 & 71 & 166 & 2 & 12 \\
\hline Rotor passage & 151 & 71 & 56 & 2 & 36 \\
\hline Rotor tip clearance & 81 & 11 & 13 & 2 & 36 \\
\hline Stator passage & 141 & 71 & 79 & 3 & 46 \\
\hline
\end{tabular}

In the previous Stage 35 stall inception work using TURBO, boundary-layer near-wall packing was employed on grids near the casing. When gridding volume in the tip clearance region "below" the casing and "above" the blade tip, the previously-appropriate unidirectional boundary-layer near-wall packing must be altered. The pitchwise view of the tip clearance grids, shown in Figure 8, reflects the revised grid spacing, with the outer eight grids equally spaced to accommodate tip clearance grids for the downstream stator and the next two grids then (independently) equally spaced above the rotor tip.

\section{TURBO Solution/Boundary Conditions}

The TURBO simulations documented herein employed the following execution and boundary conditions.

\section{Inlet Boundary Condition}

At the inlet, an isentropic condition (Ref. 3) is applied, whereby a prescribed spanwise total condition is maintained. This boundary condition preserves the upstream total conditions at the levels of the test facility, but it can potentially adversely reflect outbound pressure waves back into the computational domain (Ref. 11).

\section{Exit Boundary Condition}

At the exit plane of a compressor operating at a stable condition, prescribing radial equilibrium with a specified hub (or casing) static pressure works well. However, this boundary condition's declared exit pressure is unable to match the drops in static pressure recovery associated with rotating stall. Therefore, a new "choked" throttle model is used. This boundary condition extrapolates temperature, pressure, and tangential components of velocity to match the compressor exit mass flux corrected to the exit total condition (Ref. 7).

\section{Solution Parameters}

Throughout this study, second-order temporal accuracy and second-order spatial accuracy are applied. As has been done in prior research by Chen et al. (Refs. 7 and 8) and Hathaway et al. (Ref. 6), three Newton subiterations are applied with six symmetric Gauss-Seidel sweeps per subiteration. Previous research using these solution parameters has yielded valuable insight into the stall inception process in somewhat reasonable (computational) time.

\section{Overall Performance: Speedlines}

To gauge the overall performance of the machine and to assess the accuracy of simulations of the compressor, it is useful to plot speedline characteristics. Figure 9 shows the total-to-static pressure ratio performance versus physical mass throughflow at 100 percent speed with a tip clearance of 1 percent chord for several TURBO simulations compared to the physical experiment by Weigl (Ref. 12). In the test rig, this curve results from incrementally closing the throttle from choke to stall. The corrected mass flow exit boundary condition employed in the TURBO simulations emulates a throttle and facilitates a similar procedure for drawing a total-to-static pressure speedline. 


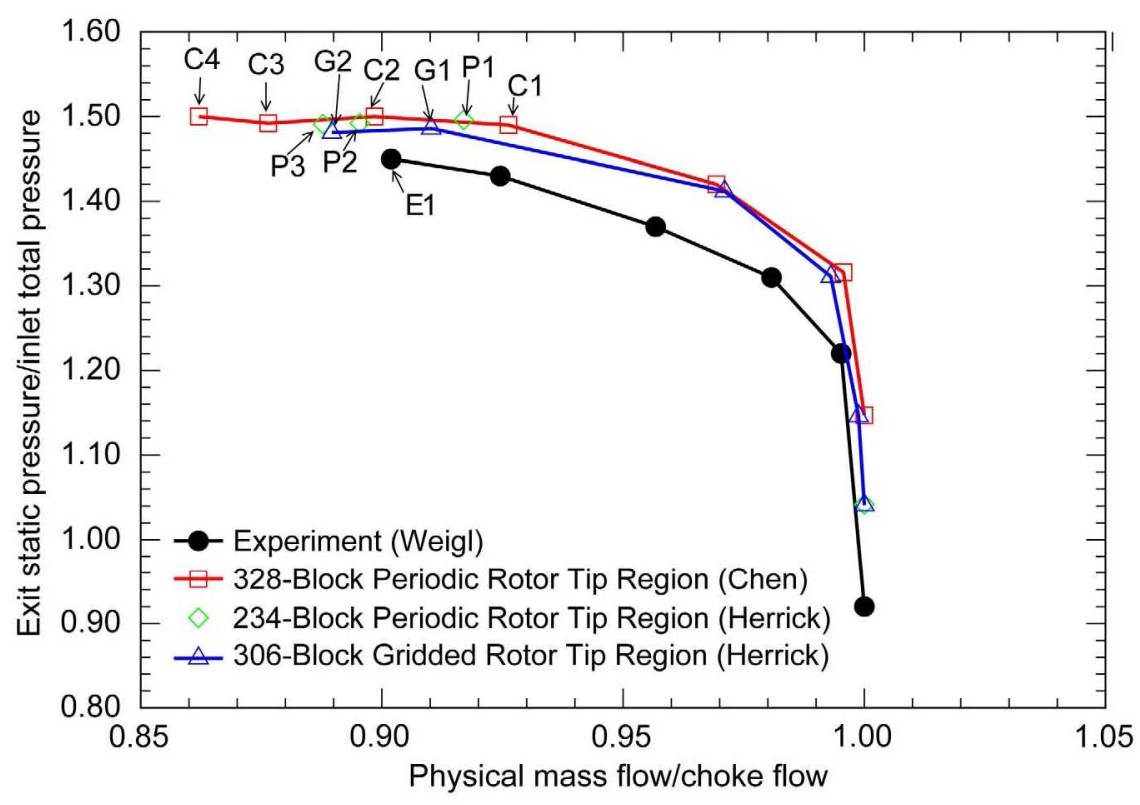

Figure 9.-Speedline characteristics for Stage 35 at 100 percent speed.

Speedlines are plotted from three TURBO simulations/configurations a 328-block configuration with periodic rotor tip clearance regions, a 234-block configuration with periodic rotor tip clearance regions, and a 306-block configuration with gridded rotor tip clearance regions. The 328-block configuration, run first by Chen and Hathaway on 328 processes, features boundary-layer near-wall grid packing along the casing wall, as it was not originally intended to include gridded rotor tip clearance regions; this grid has exactly the same unpartitioned computational extents as listed here in Table 2 but without gridded rotor tip clearances. The 234-block configuration run in this effort on 234 processes is based upon the 328-block grid of Chen and Hathaway, but it is repartitioned into 234 blocks (to conform to smaller computational cluster queues) with equal spacing between casing wall and rotor tips (to facilitate seamless addition of rotor tip clearance grids). The 306-block configuration consumed equal process-time as the 234-block configuration while providing the additional gridding in the rotor tip clearance regions; recent enhancements to the code enabled this efficient computational performance with additional gridding.

Detailed information on TURBO executions near stall is listed in Table 3. In this table, Throttle Exit $B C$ provides the exit corrected mass flow in $\mathrm{kg} / \mathrm{s}$ (corrected to exit total conditions); Casing Grid may be Boundary Layer (casing-biased) or Evenly Spaced; Mass Flow is listed in kg/s; Seed Flow indicates the initial flow condition used to initiate the flow field at the new throttle setting; Flow Condition may be Stable, at the Precipice to Stall (i.e., mass flow and static pressure recovery are about to plummet at this operational condition), or exhibiting potential of going Unstable.

TABLE 3.-DETAILED PERFORMANCE DATA FOR TURBO SIMULATIONS NEAR STALL

\begin{tabular}{|c|c|c|c|c|c|c|c|c|}
\hline Point & Throttle exit BC & Rotor clearance & Casing grid & $\begin{array}{c}\text { Block } \\
\text { count }\end{array}$ & Mass flow & Pse/Pti & Seed flow & $\begin{array}{c}\text { Flow } \\
\text { condition }\end{array}$ \\
\hline C1 & 14.60 & Periodic & Boundary layer & 328 & 19.34 & 1.490 & -- & Stable \\
\hline C2 & 14.07 & Periodic & Boundary layer & 328 & 18.76 & 1.500 & C1 & Stable \\
\hline C3 & 13.80 & Periodic & Boundary layer & 328 & 18.30 & 1.492 & C2 & Precipice \\
\hline C4 & 13.60 & Periodic & Boundary layer & 328 & 18.00 & 1.500 & C2 & Precipice \\
\hline P1 & 14.40 & Periodic & Evenly spaced & 234 & 19.16 & 1.496 & -- & Stable \\
\hline P2 & 14.10 & Periodic & Evenly spaced & 234 & 18.17 & 1.492 & P1 & Unstable? \\
\hline P3 & 14.00 & Periodic & Evenly spaced & 234 & 18.55 & 1.491 & P2 & Precipice \\
\hline G1 & 14.40 & Gridded & Evenly spaced & 306 & 19.01 & 1.486 & -- & Stable \\
\hline G2 & 14.10 & Gridded & Evenly spaced & 306 & 18.58 & 1.481 & G1 & Precipice \\
\hline
\end{tabular}


As shown in Figure 9, TURBO exhibits similar, but slightly higher, choking mass flow rates as experiment. TURBO's choking mass flow rate and choking pressure ratio are identical for the 234-block simulations with periodic tip clearances and the 306-block simulations with gridded tip clearances. Chen and Hathaway did not document as deep a choked condition. Throttling down from choke, the 306-block gridded tip configuration of the present study shows a general trend toward very slight reductions in mass flow and pressure ratio in comparison with the original 328-block periodic tip configurations of Chen and Hathaway; these deviations represent nominal, minimal improvements in TURBO's predictions versus experiment. As the throttle is closed, the current 234-block simulation employing periodic rotor tip clearances has point $\mathrm{P} 1$ lying nearly collinear between points $\mathrm{C} 1$ and $\mathrm{C} 2$ from the original 328-block simulations, also employing periodic rotor tip clearances, implying that the enhanced code is maintaining the numerical performance of the original code and that the slight differences in gridding near the case are inconsequential at this stable flow condition. The current 306-block simulation employing gridded rotor tip clearances has point $\mathrm{G} 1$ lying between $\mathrm{C} 1$ and $\mathrm{C} 2$ in mass flow but with slightly reduced - and slightly closer to experiment - static pressure recovery.

In the original TURBO simulations of Stage 35 by Chen and Hathaway, the last stable point (C2) exhibits a virtually identical mass flow rate with the last stable point observed in experiment (E1); TURBO's prediction of static pressure recovery is higher than experiment. In the present TURBO simulations of Stage 35, no definitively stable operating condition is found near the stalling mass flow rate of experiment (E1) and previous TURBO simulation (C2). The simulations yielding G2 (gridded tip) and P3 (periodic tip) operate quasi-stably in this vicinity for quite awhile before weakening and stalling, and the simulation yielding P2 appears to be weakening as the simulation is suspended due to time and resources constraints. Points P2 and P3 of the current 234-block periodic tip simulations are showing reductions in static pressure recovery in comparison with $\mathrm{C} 2$ and $\mathrm{C} 3$ from the previous 328-block periodic tip simulations, presumably due to the differences in casing boundary layer gridding.

Though at a lower mass flow rate than experiment (E1), points G2 and P3 do show good agreement with one another with regard to stalling mass flow and stalling pressure recovery. This inspires confidence that the TURBO-predicted stalling condition for this compressor is unaffected by the slight differences in handling of the rotor tip clearance regions. However, points P3 and G2 represent different throttle settings and the lengths of their stall-inception transients differ. Additionally, point P2 has the same throttle setting as $\mathrm{G} 2$, yet the different treatments of rotor tip clearance flow are clearly yielding differing performances over time for these two simulations. For a given exit boundary condition (prescribed exit corrected mass flow), the gridded tip clearance configurations tend to allow less throughflow and facilitate less static pressure recovery, presumably due to additional blockage in the rotor tip clearance region.

\section{Aerothermodynamic Performance Approaching Choke}

It is also instructive to investigate TURBO's capabilities for predicting aerothermodynamic performance of this compression system. Aerothermodynamic performance data for Stage 35 was collected and documented by Reid and Moore (Ref. 5). This experimental data was collected at discrete locations and mass-averaged about the annulus to determine aerothermodynamic compressor performance parameters. Four performance parameters are of primary interest for current NASA research efforts validating computational simulations of compressors: total pressure ratio, total temperature ratio, adiabatic efficiency, and exit flow angle.

Because TURBO is a time-accurate, unsteady CFD code, it captures a multitude of flow features and perturbations of varying frequency inherent in turbomachinery flows. Due to the nature of physical experiment and measurement, test data collected and interpreted for Stage 35 depict a temporally and spatially averaged representation of the flow rather than the "instant in time", "point in space" data interrogation possible with TURBO. Because the primary objective of low flow condition simulations focuses on capturing the temporal and spatial evolution of stall inception, time-averaged simulation solution data is not collected and analyzed for the low flow, near stall conditions. The flow approaching 


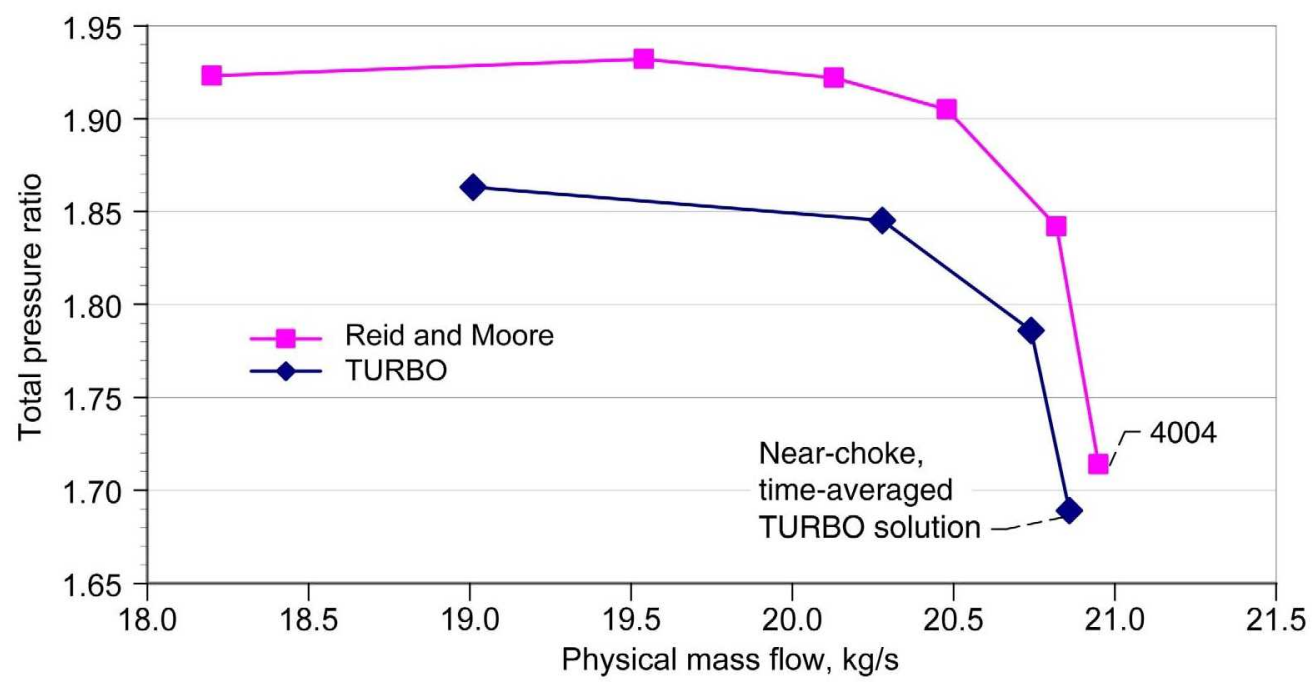

Figure 10.- Stage 35 total pressure ratio speedline.

choke also exhibits temporal and spatial variation, but to a much lesser degree; time-averaged solution data for flow approaching choke is collected and analyzed here.

The speedline characteristics comparing TURBO versus Reid and Moore experiment on total-to-total pressure ratio are shown in Figure 10. TURBO simulations are executed with exit boundary conditions of $20.00 \mathrm{~kg} / \mathrm{s}$ corrected mass flow, yielding a mass flow similar to Reid and Moore's point 4004 . As shown in Table 4, this TURBO simulation at near-choke is indeed very close to the experimental data point in terms of mass flow, total temperature ratio, total pressure ratio and adiabatic efficiency. TURBO's deviation in this simulation is within the bounds of experimental uncertainty cited by Reid and Moore (Ref. 5).

TABLE 4.-STAGE 35 AEROTHERMODYNAMIC PERFORMANCE APPROACHING CHOKE

\begin{tabular}{|l|c|c|c|c|}
\hline \multicolumn{1}{|c|}{ Parameter } & $\begin{array}{c}\text { Experiment point } \\
4004\end{array}$ & TURBO near-choke & $\begin{array}{c}\text { Experiment uncertainty, } \\
\text { Percent }\end{array}$ & $\begin{array}{c}\text { TURBO deviation, } \\
\text { Percent }\end{array}$ \\
\hline Stage total pressure ratio & 1.714 & 1.689 & 1.9 & 1.5 \\
\hline Stage total temperature ratio & 1.198 & 1.193 & 0.46 & 0.42 \\
\hline Stage adiabatic efficiency & 0.841 & 0.837 & 0.99 & 0.48 \\
\hline Mass flow, $\mathrm{kg} / \mathrm{s}$ & 20.95 & 20.86 & 1.4 & 0.4 \\
\hline
\end{tabular}

Beyond the stator exit in the physical experiment, two combination probes were traversed circumferentially among nine locations within the stator gap, while two wedge probes were separately located and diametrically opposed at stator midgap. Four static pressure taps were mounted on the hub surface, and an additional four static pressure taps were mounted on the casing surface beyond the stator exit. Forward of the rotor, two combination probes were diametrically opposed, and one wedge probe was used. As with the stator exit, four static pressure taps were placed on the hub and casing surfaces alike. All combination and wedge probes were sequenced through nine radial positions to gather spanwise data of total pressure, total temperature, and flow angle.

With TURBO, similar data may be extracted with much finer geometric precision: The TURBO grid contains 70 volumes between hub and case (including 10 volumes spanwise in the tip gap) and 78 volumes between adjacent vane surfaces. As was done with the coarser grid from the experiment, TURBO data is mass averaged to calculate appropriate aerothermodynamic performance parameters. Total pressure data is plotted in Figure 11. As was the case for the overall total pressure ratio (across the full inlet and exit planes), TURBO is again generally predicting somewhat low, but the trends of total pressure ratio from hub to case are very well captured by TURBO; TURBO's maximum deviation from experimental point 4004 is about 2 percent. 


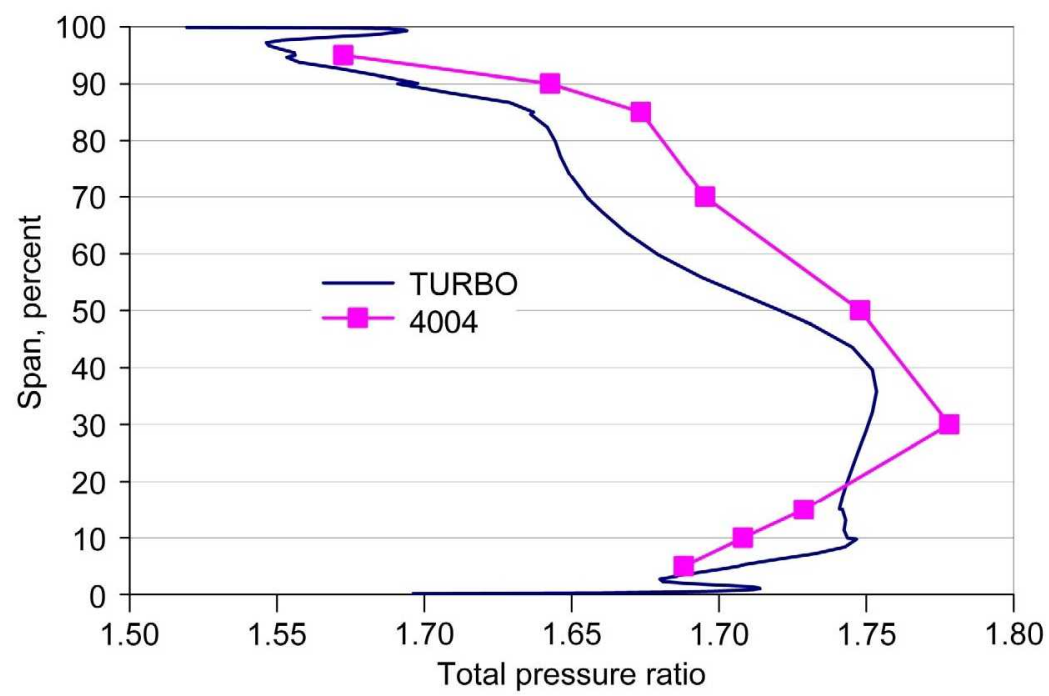

Figure 11.-Stage 35 total pressure ratio at stator exit.

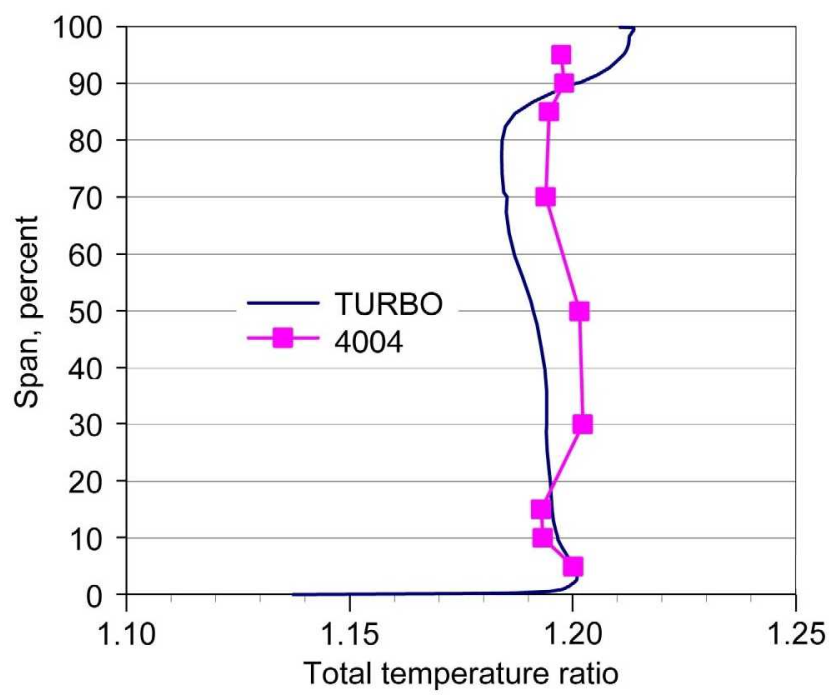

Figure 12.-Stage 35 total temperature ratio at stator exit.

In Figure 12, stage total temperature ratio data is plotted. TURBO is predicting slightly lower total temperature ratio than the experimental data purports. TURBO and experiment show different trends from 15 percent span to 30 percent span, where experiment revealed an increase in total temperature ratio versus the near-hub regions but TURBO shows total temperature ratio to be rather constant in this region. TURBO captures well the trend of total temperature ratio from 30 to 70 percent span. TURBO's maximum midspan deviation is about 1 percent.

Adiabatic efficiency is easily derived from total pressure ratio and total temperature ratio. The radial distribution of stage adiabatic efficiency is shown in Figure 13. TURBO agrees very well with experiment in magnitude and trend throughout the span, though TURBO is about 2.5 percent high at 50 percent span. Results for Stator Exit Flow angle follow in Figure 14. TURBO is underpredicting flow angle by about $3^{\circ}$ throughout the span; similar computational results have been demonstrated with other CFD codes, prompting questions about the experimental results (measurements and post-processing). This flow angle deviation exceeds the experimental uncertainty of $\pm 1^{\circ}$. 


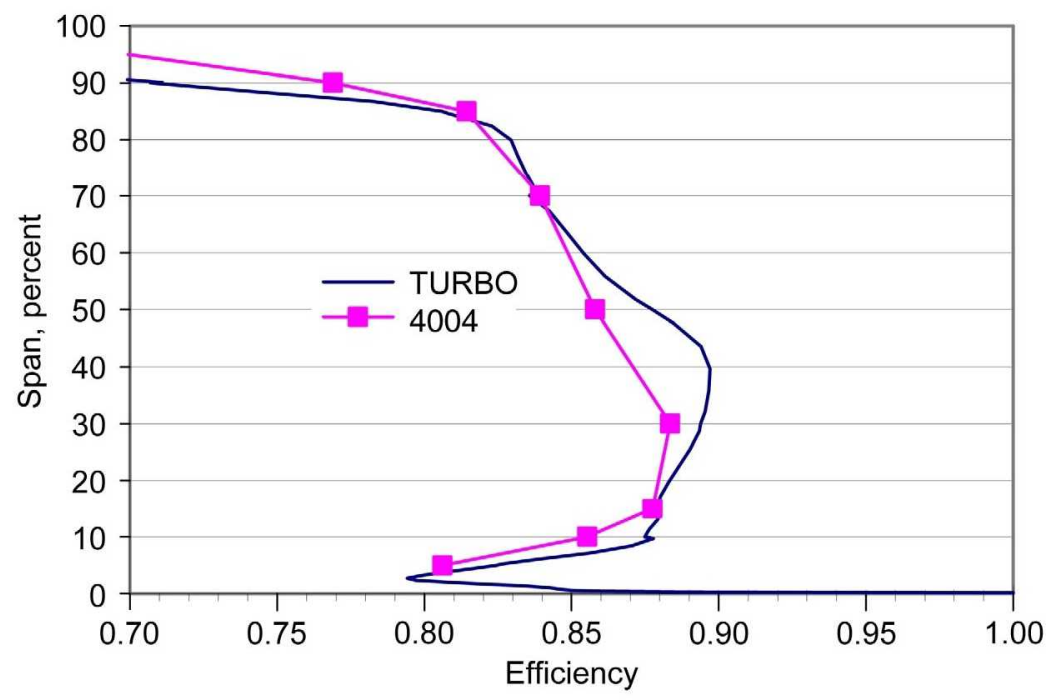

Figure 13.-Stage 35 adiabatic efficiency.

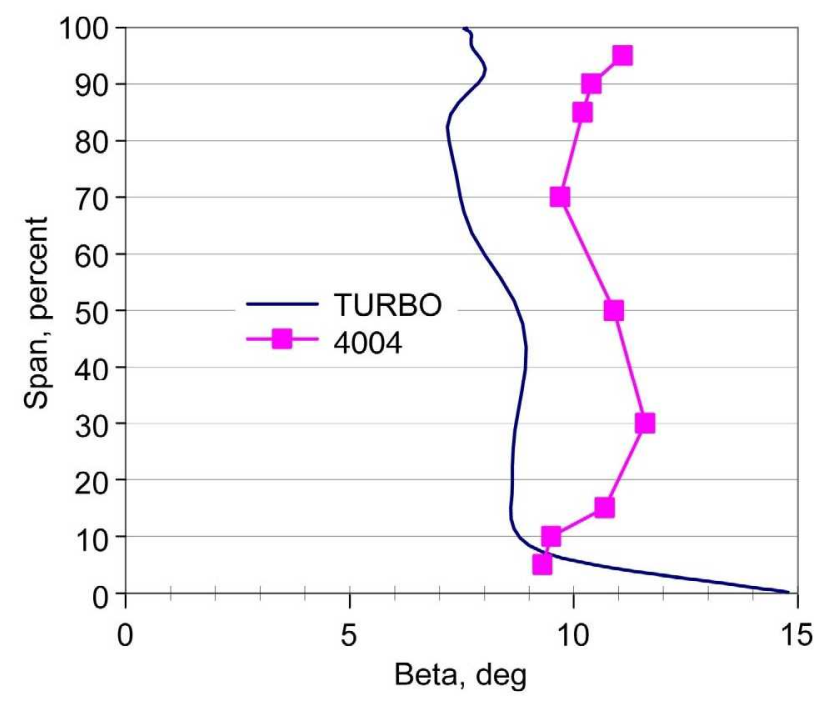

Figure 14.-Stage 35 stator exit flow angle.

\section{Conclusions and Recommendations}

A two-pronged computational research endeavor has been completed with the TURBO code. For each task, TURBO results have been compared and validated with relevant experiments. While overpredicting static pressure recovery slightly, TURBO reveals a very accurate flow range from choke to stall, and TURBO captures the unstable, temporally unsteady, spatially aperiodic flows associated with stall inception in high-speed transonic compressors when such fidelity is required. In analyzing fundamental aerotheromodynamic compressor performance at a near choke condition, TURBO only slightly underpredicts total pressure ratio and total temperature ratio. TURBO's predictions of adiabatic efficiency are quite accurate for most of the span. TURBO's underprediction of stator exit flow angle corroborates similar results from other CFD codes; exceeding experimental uncertainty, this common discrepancy should be investigated. 
The TURBO simulations, employing full annulus geometry, are quite computationally costly. These simulations have proven reliable in investigating unsteady, aperiodic, chaotic, complicated flow physics; these simulations have also proven nicely accurate for fundamental aerothermodynamic performance analysis, though results of similar quality may be attained with other CFD codes at much reduced computational cost.

\section{References}

1. Zhu, J. and Shih, T.H., "CMOTT Turbulence Module for NPARC," Tech. Rep. CR-204143, National Aeronautics and Space Administration, Aug. 1997.

2. Chen, J.-P. and Barter, J., "Comparison of Time-Accurate Calculations for the Unsteady Interaction in Turbomachinery Stage," Tech. Rep. AIAA-1998-3292, American Institute of Aeronautics and Astronautics, 1998.

3. Chen, J.-P. and Whitfield, D.L., "Navier-Stokes Calculations for the Unsteady Flowfield of Turbomachinery," Tech. Rep. AIAA-1990-0676, American Institute of Aeronautics and Astronautics, 1993.

4. Chen, J.-P. and Briley, W.R., "A Parallel Flow Solver for Unsteady Multiple Blade Row Turbomachinery Simulations," Tech. Rep. 2001-GT-0348, ASME TURBO Expo, New Orleans, Louisiana, 2001.

5. Reid, L. and Moore, R.D., "Performance of single-stage axial-flow transonic compressor with rotor and stator aspect ratios of 1.19 and 1.26, respectively, and with design pressure ratio of 1.82," Tech. Rep. TP-1338, National Aeronautics and Space Administration, 1978.

6. Hathaway, M.D., Chen, J., Webster, R.S., and Herrick, G.P., "Time Accurate Unsteady Simulations of the Stall Inception Process in the Compression System of a U.S. Army Helicopter Gas Turbine Engine," 2004 DoD High Performance Computing Modernization Program Users Group Conference, Williamsburg, Virginia, June 2004.

7. Chen, J.-P., Webster, R.S., Hathaway, M.D., Herrick, G.P., and Skoch, G.J., "Numerical Simulation of Stall and Stall Control in Axial and Radial Compressors," Tech. Rep. AIAA-2006-0418, American Institute of Aeronautics and Astronautics, 2006.

8. Chen, J.-P., Hathaway, M.D., and Herrick, G.P., "Pre-stall Behavior of a Transonic Axial Compressor Stage via Time-Accurate Numerical Simulation," Tech. Rep. 2007-GT-29627, ASME Turbo Expo 2007, May 2007.

9. Bright, M.M., Qammar, H.K., and Wang, L., "Investigation of Pre-Stall Mode and Pip Inception in High-Speed Compressors Through the Use of Correlation Integral," ASME Journal of Turbomachinery, vol. 121, 1999, pp. 743-750.

10. Kirtley, K.R., Beach, T.A., and Adamczyk, J.J., "Numerical Analysis of Secondary Flow in a TwoStage Turbine," Tech. Rep. AIAA-1990-2356, American Institute of Aeronautics and Astronautics, 1990.

11. Chen, J.-P., Hathaway, M.D., and Herrick, G.P., "Prestall Behavior of a Transonic Axial Compressor Stage via Time-Accurate Numerical Simulation," ASME Journal of Turbomachinery, vol. 130, 2008.

12. Weigl, H.J., Paduano, J.D., Frechette, L.G., Epstein, A.H., Greitzer, E.M., Bright, M.M., and Strazisar, A.J., "Active Stabilization of Rotating Stall and Surge in a Transonic Single Stage Axial Compressor," ASME Journal of Turbomachinery, vol. 120, 1998, pp. 625-636. 


\begin{tabular}{|c|c|c|c|c|c|}
\hline \multicolumn{5}{|c|}{ REPORT DOCUMENTATION PAGE } & $\begin{array}{c}\text { Form Approved } \\
\text { OMB No. 0704-0188 }\end{array}$ \\
\hline \multicolumn{6}{|c|}{ 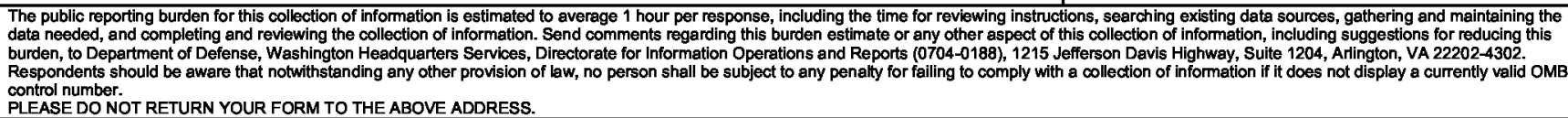 } \\
\hline \multicolumn{2}{|c|}{$\begin{array}{l}\text { 1. REPORT DATE (DD-MM-YYYY) } \\
01-05-2009\end{array}$} & \multicolumn{3}{|c|}{$\begin{array}{l}\text { 2. REPORT TYPE } \\
\text { Technical Memorandum }\end{array}$} & 3. DATES COVERED (From - To) \\
\hline \multirow{3}{*}{\multicolumn{5}{|c|}{$\begin{array}{l}\text { 4. TITLE AND SUBTITLE } \\
\text { Unsteady Full Annulus Simulations of a Transonic Axial Compressor Stage }\end{array}$}} & 5a. CONTRACT NUMBER \\
\hline & & & & & 5b. GRANT NUMBER \\
\hline & & & & & 5c. PROGRAM ELEMENT NUMBER \\
\hline \multirow{3}{*}{\multicolumn{5}{|c|}{$\begin{array}{l}\text { 6. AUTHOR(S) } \\
\text { Herrick, Gregory, P.; Hathaway, Michael, D.; Chen, Jen-Ping }\end{array}$}} & 5d. PROJECT NUMBER \\
\hline & & & & & 5e. TASK NUMBER \\
\hline & & & & & $\begin{array}{l}\text { 5f. WORK UNIT NUMBER } \\
\text { WBS 561581.02.08.03.21.03 }\end{array}$ \\
\hline \multicolumn{5}{|c|}{$\begin{array}{l}\text { 7. PERFORMING ORGANIZATION NAME(S) AND ADDRESS(ES) } \\
\text { National Aeronautics and Space Administration } \\
\text { John H. Glenn Research Center at Lewis Field } \\
\text { Cleveland, Ohio 44135-3191 }\end{array}$} & $\begin{array}{l}\text { 8. PERFORMING ORGANIZATION } \\
\text { REPORT NUMBER } \\
\text { E-16895 }\end{array}$ \\
\hline \multirow{2}{*}{\multicolumn{5}{|c|}{$\begin{array}{l}\text { 9. SPONSORING/MONITORING AGENCY NAME(S) AND ADDRESS(ES) } \\
\text { National Aeronautics and Space Administration } \\
\text { Washington, DC 20546-0001 } \\
\text { and } \\
\text { U.S. Army Research Laboratory } \\
\text { Adelphi, Maryland 20783-1145 }\end{array}$}} & $\begin{array}{l}\text { 10. SPONSORING/MONITOR'S } \\
\text { ACRONYM(S) } \\
\text { NASA; ARL; AIAA }\end{array}$ \\
\hline & & & & & $\begin{array}{l}\text { 11. SPONSORING/MONITORING } \\
\text { REPORT NUMBER } \\
\text { NASA/TM-2009-215604; AIAA-2009- } \\
1059\end{array}$ \\
\hline \multicolumn{6}{|c|}{$\begin{array}{l}\text { 12. DISTRIBUTON/AVAILABILITY STATEMENT } \\
\text { Unclassified-Unlimited } \\
\text { Subject Categories: } 02 \text { and } 07 \\
\text { Available electronically at http://gltrs.grc.nasa.gov } \\
\text { This publication is available from the NASA Center for AeroSpace Information, 301-621-0390 }\end{array}$} \\
\hline \multicolumn{6}{|c|}{ 13. SUPPLEMENTARY NOTES } \\
\hline \multicolumn{6}{|c|}{$\begin{array}{l}\text { 14. ABSTRACT } \\
\text { Two recent research endeavors in turbomachinery at NASA Glenn Research Center have focused on compression system stall inception and } \\
\text { compression system aerothermodynamic performance. Physical experiment and computational research are ongoing in support of these } \\
\text { research objectives. TURBO, an unsteady, three-dimensional, Navier-Stokes computational fluid dynamics code commissioned and } \\
\text { developed by NASA, has been utilized, enhanced, and validated in support of these endeavors. In the research which follows, TURBO is } \\
\text { shown to accurately capture compression system flow range-from choke to stall inception-and also to accurately calculate fundamental } \\
\text { aerothermodynamic performance parameters. Rigorous full-annulus calculations are performed to validate TURBO's ability to simulate the } \\
\text { unstable, unsteady, chaotic stall inception process; as part of these efforts, full-annulus calculations are also performed at a condition } \\
\text { approaching choke to further document TURBO's capabilities to compute aerothermodynamic performance data and support a NASA code } \\
\text { assessment effort. } \\
\text { 15. SUBJECT TERMS } \\
\text { Turbomachinery; Compressor; Stage; Transonic; Rotor; Stator; Navier-Stokes; CFD; Unsteady; Full annulus }\end{array}$} \\
\hline \multicolumn{3}{|c|}{ 16. SECURITY CLASSIFICATION OF: } & $\begin{array}{l}\text { 17. LIMITATION OF } \\
\text { ABSTRACT }\end{array}$ & $\begin{array}{l}\text { 18. NUMBER } \\
\text { OF }\end{array}$ & $\begin{array}{l}\text { 19a. NAME OF RESPONSIBLE PERSON } \\
\text { STI Help Desk (email:help@sti.nasa.gov) }\end{array}$ \\
\hline $\begin{array}{l}\text { a. REPORT } \\
\text { U }\end{array}$ & $\begin{array}{l}\text { b. ABSTRACT } \\
\text { U }\end{array}$ & $\begin{array}{l}\text { C. THIS } \\
\text { PAGE } \\
\text { U }\end{array}$ & & $\begin{array}{l}\text { PAGES } \\
18\end{array}$ & $\begin{array}{l}\text { 19b. TELEPHONE NUMBER (Include area code) } \\
\text { 301-621-0390 }\end{array}$ \\
\hline
\end{tabular}



